\title{
Clinical Profile of Scurvy in Hamilton Since 2009: a Cohort Study
}

\author{
Kayla Dadgar, $M D^{7}$ (1) and John Neary, $M D^{2}$
}

'Department of Medicine, University of Ottawa, Ottawa, ON, Canada; ${ }^{2}$ Department of Medicine, McMaster University, Hamilton, Ontario, Canada.

$\mathrm{J}$ Gen Intern Med 36(1):230-1

DOI: $10.1007 / \mathrm{s} 11606-020-05636-1$

(C) Society of General Internal Medicine 2020

\section{INTRODUCTION}

Scurvy is a clinical disease resulting from vitamin $\mathrm{C}$ deficiency. ${ }^{1,2}$ The literature contains many case reports of scurvy but no recent cohorts of adult patients or criteria for diagnosis have been published. Although scurvy does not usually occur unless plasma ascorbic acid levels are below $11 \mu \mathrm{mol} / \mathrm{L}$, it remains a clinical diagnosis due to lack of access to timely vitamin $\mathrm{C}$ testing. Anemia is the most commonly seen laboratory finding, correlating with the severity and chronicity of scurvy. ${ }^{3}$ Our objective is to describe the etiologies and clinical presentations of patients with scurvy in a cohort of patients at our centers.

\section{METHODS}

A chart review was completed of patients with vitamin $\mathrm{C}$ levels of $11 \mu \mathrm{mol} / \mathrm{L}$ or less between 2009 and 2017 in Hamilton, Ontario, Canada, using electronic records from St. Joseph's Healthcare Hamilton and Hamilton Health Sciences. Fifty-two patients were identified with vitamin $\mathrm{C}$ levels of 11 or less during the study period. Of these 52, a confident clinical diagnosis of scurvy was made in 12 patients. One additional patient had clinical features that could be attributed to either scurvy or the use of a vitamin $\mathrm{K}$ antagonist, with no clear etiology for scurvy, and was included in the clinical scurvy group. Thirty-nine patients had biochemical evidence of scurvy with no documented clinical manifestations of disease.

\section{RESULTS}

Of the thirteen patients with clinical scurvy, six were female and seven were male. Two cases were related to alcohol use disorder, three to bariatric surgery, and seven to other causes of malnutrition (persistent nausea and vomiting, purposeful

Received November 19, 2019

Revised November 24, 2019

Accepted January 3, 2020

Published online January 15, 2020 dietary restrictions, mental illness, social isolation, and dependence on others for access to food). One patient had no etiology documented.

The most commonly documented clinical findings were easy bruising, gingival bleeding, and perifollicular hemorrhages (each in 5 patients). Three patients had a hemoglobin level of less than $90 \mathrm{~g} / \mathrm{L}$, or less than $110 \mathrm{~g} / \mathrm{L}$ without a competing explanation. All patients that were provided vitamin C supplementation had rapid recovery of physical symptoms with treatment. One patient was able to walk within $24 \mathrm{~h}$ of vitamin $\mathrm{C}$ administration despite having previously been bedbound for weeks. One patient saw improvement of hemoglobin from 60 to 122 with 3 weeks of supplemental vitamin C.

\section{DISCUSSION}

Scurvy is perceived as a disease irrelevant to the developed world. Despite this, 52 hospital patients in Hamilton during our 9-year study period (2009-2017) had vitamin C levels low enough to cause scurvy. Of these 52 patients, only 13 had documented clinical evidence of scurvy in their hospital charts. The most common mechanisms of scurvy in this cohort of patients were poor vitamin $\mathrm{C}$ intake and malabsorption. The circumstances leading to poor vitamin $\mathrm{C}$ intake were variable, including alcohol use disorder, social isolation, and dependence on others for access to food. With respect to the last two factors, it is of interest that a British study showed that $40 \%$ individuals in nursing homes or residential homes over the age of $65(n=423)$ had plasma vitamin C levels below $11 \mu \mathrm{mol} / \mathrm{L}^{4}$

The most commonly documented findings in our clinical scurvy cohort were easy bruising, gingival bleeding, and perifollicular hemorrhages. Although hyperkeratosis is the first dermatologic finding in experimental scurvy, it was not mentioned in any of the patient charts we examined. ${ }^{5}$ It is unclear whether hyperkeratosis was not present or missed due to a lack of familiarity. Over half (54\%) of patients in this study had documented easy bruising. These numbers are in line with a Mayo Clinic study, in which $42 \%$ of patients with scurvy demonstrated easy bruising. ${ }^{6}$

Our results were limited by the fact that the Hamilton hospital electronic medical records do not include records 
from all outpatient clinics. Despite these limitations, our data have characterized both the primary etiologies for scurvy in these patients as well as their presenting symptoms and physical findings. The small proportion of charts that documented clinical signs of scurvy may underscore the need for greater awareness surrounding these features. Scurvy disproportionately affects vulnerable persons and improved awareness of the disease could aid in instituting preventative measures and earlier diagnosis.

Corresponding Author: Kayla Dadgar, MD; Department of Medicine, University of Ottawa, Ottawa, ON, Canada (e-mail: kadadgar@toh.ca).

\section{Compliance with Ethical Standards:}

Conflict of Interest: The authors declare that they do not have a conflict of interest.

\section{REFERENCES}

1. Lund CC, Crandon JH. Human Experimental Scurvy: and the relation of vitamin $\mathrm{C}$ deficiency to postoperative pneumonia and to wound healing. JAMA. 1941; 116(8):663-668.

2. Drummond JC. An Eighteenth Century Experiment In Nutrition. Lancet. 1935; 226(5843):459-463.

3. Cox EV. The Anemia of Scurvy. Vitam Horm. 1969; 26:635-652.

4. Bates CJ, Prentice A, Cole TJ, Van der Pols JC. Micronutrients: highlights and research challenges from the 1994-5 National Diet and Nutrition Survey of people aged 65 years and over. Br J Nutr. 1999; 82(01):7-15.

5. Peters RC. Vitamin C Requirement of Human Adults. A Report by the Vitamin C Sub-committee of the Accessory Food Factors Committee. Vitam C Requir Hum Adults. A Rep. by Vitam. C Sub-committee Accessory Food Factors Committee. 1953.

6. Olmedo JM, Yiannias JA, Windgassen EB, and Gornet MK. Scurvy: a disease almost forgotten. Int J Dermatol. 2006; 45(8):909-913.

Publisher's Note Springer Nature remains neutral with regard to jurisdictional claims in published maps and institutional affiliations. 